\title{
Confluent education: an integrative method for nursing (continuing) education
}

Anneke L Francke MA RN

Nurse and Sociologist

and Till Erkens BN RN

Nurse, Trainer and Psychotherapist, The Helen Dowling Institute for Biopsychosocial

Medicine, Rotterdam, The Netherlands

FRANCKE A L \& ERKENS T (1994) Journal of Advanced Nursing 19, 354-361

Confluent education: an integrative method for nursing (continuing) education

Confluent education is presented as a method to bridge the gap between cognitive and affective learning Attention is focused on three main characteristics of confluent education (a) the integration of four overlapping domains in a learning process (readiness, the cognitive domain, the affective domain and responsibility), (b) the promotion of personal growth and interpersonal relationships by the development of awareness, and (c) the identification and dis-identification of teacher and participants How confluent education can take place in practice is illustrated by presenting the way in which this method is applied in a nursing continuing education programme entitled 'Pain assessment and management in surgical-oncological patients'

\section{INTRODUCTION}

In the later 1960s and early 1970s, humanustic and holistic forces were increasing within modern health care In this penod, the educational literature (e g Rogers 1969) introduced an interest in reconceptualizing curnculum and instruction From the late 1980s, it seems as if there has been a new explosion of educational publications stressing the importance of considenng the indrvidual learner's feelings and expenences In some of these publications, special attention is pard to techniques which can be used in nursing education, like game-simulation (Barber \& Norman 1989) and workang with the lived expenence' (Diekelmann 1992, Smith 1992) Some other papers offer theories on which to base those activities (Burnard 1987, French \& Cross 1992), or focus on the reasons and necessity for paying more attention to affective learning processes (Miller 1989)

Correspondence Ameke L Francke. The Helen Dowitng Institute for Biopsychosocial Medicme, Mathenesserlaan 183, 3014 HA Rotterdam, The Netherlands
Nevertheless, the topic of how cognitive learning can be integrated with affective learning seems a somewhat neglected area This paper offers a description of confluent education, a method which could be a means to 'integration of the learning of the head with the learning of the heart'

In the first section of this paper, the theory of confluent education will be presented In the second section, we will illustrate how confluent education can work in practice by sharing our own expenences with this method in a nursing continuing education programme

\section{CONFLUENT EDUCATION IN THEORY}

\section{Background of confluent education}

Confluent education is influenced by several approaches belonging to the so-called 'thurd force psychology' (Maslow 1968) The influence of Gestalt therapy (Perls 1970) is probably the most pronounced, as features of this psychotherapeutical direction, like the emphasis 


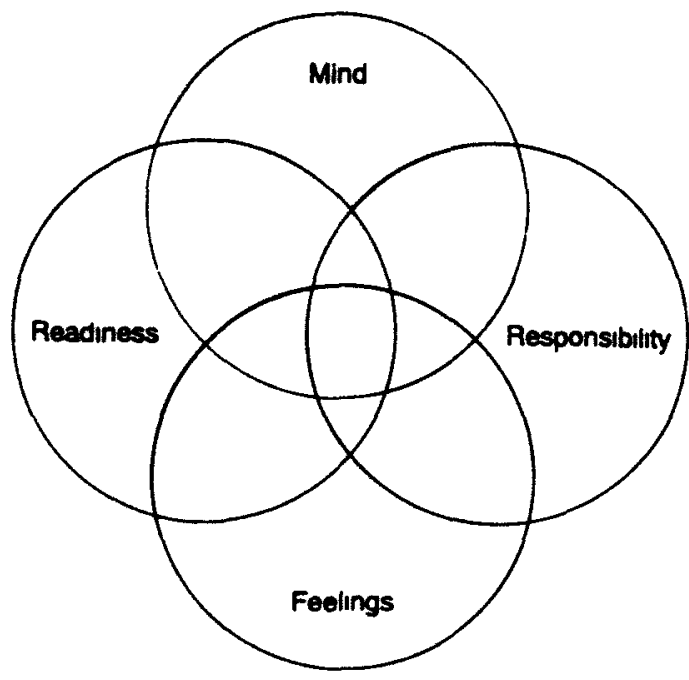

Figure 1 The four-circle model

on personal expenences in the immediate present and the use of awareness, are also found in confluent education

If both affective and cognitive components are emphasized the chances of behaviour change may be higher, in education programmes (Alexander 1990) as well as in psychotherapy (Perls 1970) However, before the 1960s, traditional curncula often placed emphasis exclusively on cognitive objectives Later approaches, often described as affective or experiential, shifted emphasis entirely toward the affective domain In reaction to this imbalance, 'confluent educators', like Brown (Brown et al 1976, Brown 1981, 1990) and Castillo (1974), assumed that teachers should be more aware of the natural relationship between affect and cognition, and initiated education projects in which this relationship was worked out

\section{Characteristics of confluent education}

The first main charactenstic of confluent education, which is demonstrated in its name, is the 'flowing together' of the cognitive elements of learning processes with the affective elements (Brown et al 1975, 1976, Brown 1981, 1990) This has been illustrated by the so-called fourcircle model (Castillo 1974), which shows four domains (Figure 1)

1 the domain of readiness

2 the cognitive domain (mind)

3 the affective domain (feelings)

4 the domain of responsibility

'Readiness' refers to the student's openness and willingness to learn about a specific topic For achieving readiness, the teacher has to create an environment in which the student feels safe, and has the idea that one should not be coerced to learn in a way one does not want to This is important in each learning process, but especially wherever affective learning is performed

The cognitive domain includes the activities of the mind, or functioning of the intellect what an individual learns, and the various intellectual processes of learning (from rote learning to learning how to learn)

The affective domain deals with how a student feels about wanting to learn, how he feels as he learns, and how he feels after he has learned (For reasons of readability, masculine pronouns are used here for students and patients, and feminine pronouns for nurses ) In other words, the affective domain refers to feelings, emotions, attitudes, values, and concern for interpersonal relationships

'Responsibility' refers to the principle that a student has to take responsibility for using what he has learned in his private or professional life Without explicit taking of responsibility, a learning process may have no effect on knowledge, attitudes or behaviour This taking of responsibility may lead to new learning questions and aims which in turn lead to readiness for the next step in the learning process

A second important characteristic of confluent education is that it aims to contribute to personal growth and improvement of interpersonal relationships by the development of awareness (Brown et al 1976) Awareness can be described as having a clear insight into one's intrapersonal process, by making use of one's senses' In other words, awareness means 'recognizing what is going on in oneself, by reflecting on what is seen, heard, felt and thought now, in this moment' According to confluent education, awareness brings people in touch with their own human qualities like empathy, compassion, patience, and non-judgement (the letting go of judgements and projections, the shoulds or oughts') In addition, awareness gives people the ability to separate what is being seen or heard from what is being imagined, and to be fully present in the here and now'

A third characteristic of confluent education is that this method stresses the importance of 'identification and dis-identification' In this context, to identify means 'to go beyond one's own intrapersonal boundanes and to associate with the other person' To dis-identify means to disassociate afterwards and to return to one's own boundanes' When there is identification and real contact between human beings one could speak of an 'I-Thou' relationshup (Buber 1981), but when there is little 
Table 1 What often happens in these situations?

Between mothers and children? In education programmes? In nursing care?

The mother feels cold and she projects her coldness on the chuld and presses the child to put on a cardigan The mother decides whether the child is cold or warm

The mother does not realize her own projection Instead of looking after herself, the mother takes care of her daughter as if the chuld always has the same expenences as herself

This prevents both mother and child from developing their own awareness' and becoming autonomous people
The teacher decides what the participants should know and how they should learn it The theoretical framework used by the teacher is, therefore, not always famuliar to the participants, and it is often poorly applicable in practice

The teacher does not realize that his/her way of thinking does not really match the world of the participants' expenence and that he/she takes over the participants' responsibility This results in 'I know what you should know'

Participants are (not) aware of the teacher s position of power and express this by means of admission ("you're nght") or by displeasure The learning process is hindered by this
The nurse thinks that the pahent is in pain and she says, without asking about the patient's needs 'I can see that you are in great pain I'll give you a painkaller'

The nurse does not realize that she is giving a personal interpretation of someone else's feelings/emotions Netther does she realize that it is important to ask the patient whether her observations are correct or what the patient's wishes are

The patient is (not) aware of his subordinate position and often leaves the decision to the nurse as she is the 'expert' This reinforces the separation from and dependence of patients on health care workers identification and one person treats another as an object, this could be described as an 'I-It' relationshup (Brown 1981) In education programmes for nurses (or other health care workers), participants could be taught how to identify and dis-identify with patients After the identification, the dis-identification is important to prevent a 'total symbiosis' (e $\mathrm{g}$ of teacher-student or nurse-client)

\section{Awareness, Identification and dis-ıdentıfication}

What can happen when awareness and the process of identification and dis-identification are lacking, can be llustrated by the remark of a nine-year-old girl who told us 'When my mother gets cold, she makes me put on a cardigan' The gurl expressed in her own words that her mother projects her own feelings and needs on her daughter (This of course may also happen in other parent-chuldren relationshups, e g fathers and sons) In teacher-student relationships where the teacher is not aware of his/her own processes and the student's, and in which the teacher takes all the responsibility, we have an analogous situation Also in nursing practice we often see a similar phenomenon a nurse may assume that her own awareness is the same as the patient's, and that for this reason she can decide what is best for the patient

On the basis of the girl's remark, we may ask the questions shown in Table 1

According to confluent education, a person (e g parent, teacher or nurse) has to be aware of his/her own intrapersonal process Out of this awareness real communication can occur ('I think or feel this what about you '), and out of this contact an intervention (e g putting on a cardigan, choosing how to learn or giving painkillers) can be chosen Awareness may lead to taking responsibility for oneself and to giving the other person the opportunity to become aware and responsible This leaves responsibilities where they belong, without taking them over from or forang them on other people This approach is demonstrated in Table 2

It is important in an education process, as well as in other interpersonal processes, to make a clear distinction between 'mine' and 'yours', that is, to recognize one's own feelings and attitudes and not project them on the other Then real contact becomes possible a genune response is made to the other's question, and the ' $T$ ' and 'Thou' relationship, in Buber's (1970) sense, starts to work. 
Table 2 How can thungs go differently?

In parent-chuld relationshups?

The mother realizes that she herself would like to put on something warm and comfortable and takes care of herself She is aware of her own coldness This 'awareness' causes her to tell her daughter $I$ am cold', and to ask 'What about your' and 'Would you like to put on a cardigan too?'

In this way, the child is enabled to be aware of her own feelings and to decide what she needs
In contınuing education programmes?

In actual nursing practice?
The teacher realizes that the learning process of each participant is unique $\mathrm{He} / \mathrm{she}$ also realizes that his/her relation with the participants determines the learning results This 'awareness' causes the teacher to tell the participants II would like to be in keeping with your wishes, knowledge and experience Therefore, I will indicate what will be taught, but I invite you to decide with me how you want to learn this'

On the basis of the participants' answers and questions, the teacher decides what should be done for the partıcipants to gan clear insight into the theory In this way, it is possible to increase knowledge and skills In addition, responsibility for the entire learnung process will be shared
The nurse realizes what happens to her in contact with the patient This 'awareness' causes her to ask the patient 'How are you feeling? Are you in pain? And if so, how would you describe your pain?' and 'What would you like me to do for you at this moment?

On the basis of the patient's answer, the nurse chooses her interventions which are included in the expertise of a nurse

\section{CONFLUENT EDUCATION IN PRACTICE. AN ILLUSTRATION}

\section{General remarks}

In the previous section, we described confluent education in rather abstract terms In this section, we want to paint a more concrete picture of confluent education, by shanng our own experiences with this method in a nursing contınuing education programme entitled pain assessment and management in surgical-oncological patients' To clarify the broader context of this programme, we will first give some background information

\section{Background of the programme}

The primary stimuli for developing our programme were shortcomings in cancer nursing education and practice concerning pain assessment and management (Pritchard 1988, Paice et al 1991, Francke 1992, Theeuwen \& Francke 1992) Briefly the aim of the programme was to reduce the postoperative pain of surgical-oncological patients by improving nurses' pharmacological and nonpharmacological (including psychosocial) pain-reducing interventions

In 1991, the effectiveness of a 'try-out' of the programme was assessed (Erkens \& Francke 1993) Nursing participants reported positive effects on their pain management, in questionnaires and evaluation interviews These findings gave nise to the current phase of the study (1992-1994), in which the effects of the programme (on nurse and patient outcomes) are being further assessed in Dutch general hospitals The programme is implemented in 8 weekly sessions of 3 hours each Participants are registered nurses working with surgical cancer patients

\section{The development of a plan}

Before developing a structured plan for our programme, participant observations and semi-structured interviews among nurses and surgical cancer patients were conducted (Francke 1992, Theeuwen \& Francke 1993) An important finding was that Dutch nurses consider psychosocial support in the area of pain management very important However, they often do not know what to say or do and frequently feel powerless in canng for patients suffening very severe postoperative pain Furthermore, it was found that few nurses know how to make use of simple non-pharmacological techniques (like relaxation exercises) Another finding was that nurses often give less and more irregular pain medication than advised by pain experts (e g McCaffery \& Beebe 1989) 
Besides these observations and interviews, an analysis of written learning wishes of nurses who participated in the 'try-out' was conducted A rather frequent learning wish was the extension of skills, especially in the field of giving psychosocial support to postoperative patients with pain

After these inventones, the plan for the programme was drawn up This plan was important for a systematic arrangement and presentation of ideas In addition, the plan also functioned as a means to make clear to our supervision committee the exact content of the programme It was also helpful during the programme, especially in the phases of creating readiness The teachers could systematically compare the learning goals and planned actions formulated in the plan with the goals and wishes of the participants A structured plan is always used as a 'gurde-book' in confluent education and not as an 'unassallable bible' When what the participants presented did not match with what was planned in a particular session, the plan was adjusted for this particular group and for this part of the programme Of course, these adjustments were only made when the here-andnow' wishes of the participants corresponded with the theme 'pain assessment and management in surgical cancer patients' When that was the case, the teachers and students in the first instance started to work with the participants' wishes In this way, readiness was created to deal in the second instance with what onginally was planned

\section{Description of the first session}

In this paragraph we will describe the first session of the 'try-out' of the programme by using the four-circle model The themes of this session were 'What is pain' and 'Identifying and dis-identifying with surgicaloncological patients in pain'

\section{Readiness (arcle 1 in Figure 1)}

In the first instance, readiness was achieved with a group conversation to get acquainted Teacher and participants got to know each other by describing their personal background (e $g$ name and age) and their professional life (e $g$ work expenences) In the second instance, readiness was created by an individual written assignment on the basis of questions such as

1 'Why did you choose this course?'

2 'What do you want to do/learn in this course?'

3 'What don't you want to do/learn on any account?'

4 When will you experience this programme as successful?'
With this assignment and the group stock-takıng afterwards, wishes and expectations became more explicit In addition, the participants could observe one another's reactions and become aware of similanties and differences On the basis of the participant's reactions, the teacher could make a definitive decision on the theme of this session Whether this theme should be dealt with by means of transfer of knowledge or by affective techniques could also be determined then In this case, it was decided to continue in a cognitive way One reason for this decision was that some participants shared their fear that too much emphasis would be placed in the programme on techniques like role-playing

These actions created the beginning of a safe, open atmosphere and joint responsibility for the success of the continuing education programme

\section{Cognitive domain (arcle 2)}

The participants then received an assignment to work in parrs and determine what they knew about the sort of pain surgical-oncological patients may expenence Subsequently, using flp-over sheets, teacher and participants together divided pain (Erkens 1991) into

1 pain felt on and in the body

2 mental pain (e $\mathrm{g}$ confusion)

3 emotional pain (e g frustration due to inability to release feelings and emotions)

4 existential pain (e $\mathrm{g}$ loss of hope)

The participants were told that these different types of pain often influence each other Nevertheless, this somewhat artificial distinction is frequently necessary in order to come to a well-founded choice for adequate nursing interventions

\section{Affective domain (arcle 3)}

An exercise was then carned out The participants were asked to split up into groups of three and to assume the following roles person $A$, a surgical cancer patient in pain, person $B$, a nurse, and person $C$, an observer who frequently asks for time out to make both $A$ and $B$ aware of what is going on, and to let them share these experiences

The persons $A, B$ and $C$ all received the assignment to obtain information on

1 The content of pain, including the location and nature of A's pain

2 The intrapersonal process of person $A$, including how A experiences the pain

3 The intrapersonal process of person $B$, including how $B$ expenences communicating with a person in pain 
4 The content of care, that is the things $B$ says and does to relieve A's pain

5 The process of care, that is the climate of atmosphere $B$ creates to give $A$ the opportunity to express himself in such a way that $B$ really understands what A means

Through exercising each of the three roles, the participants could create an awareness of what was going on in themselves and in the other This was necessary to fully understand that pain is a subjective feeling, that pain is what the patient says it is, and that pain is as severe as the patient says it is (McCaffery 1979)

Finally, during this exercise the participants learned to distinguish between pain of a patient with regard to content, and pain with regard to process While identifying with a patient, a nurse may experience that it is essentral not only to pay attention to the pain itself, but also to the patient's intrapersonal process when he is in pain This is important in nursing when a patient feels that a nurse pays attention to his expenences and feelings connected to pain, this may bring about emotional relief, which in turn may reduce the pain physically felt

\section{Responsibulity (circle 4)}

The phase was then reached in which the participants evaluated the first session This evaluation was initiated by the following question 'Could you please look back for a moment and clanfy for yourself what you have become aware of in this session, and what you have learned?

Learning can be enhanced greatly when the subject matter is perceived by the participant as relevant (Keltner 1983, Wake 1987) For this reason, it is important to make a connection with everyday life and work This was done by means of the following question and assignment 'Do you think that you will apply what you have now learned or discovered, tomorrow or later in your professional or private life? Take some time to think about it, and when you're finished, find yourself a partner, tell each other about your intentions, and don't forget that "small steps" will increase the chance of success and satisfaction" In this way, the participants could take the responsibility of applying (or not applying) what they had learned Some participants also became more aware of questions concerning the subject matter which were still left unanswered This illustrates how creating responsibility may also lead to a new readiness $A$ few illustrative remarks of participants

The moment you asked us what we would like to learn, I noticed that I thought and felt that you were the one to decide that Later on I discovered that I thought I should know everything about pain I have worked at an oncological ward for more than three years now This thought, that I ought to know everythung, often makes me feel powerless Am I the only one who thunks like this? And would it be possible to pay attention in the next session to the subject of feeling powerless? I find this important because this feeling sometimes comes over me with patients who are in pain

I discovered that it helps me to distinguish between physical pain, mental pain, emotional pain, and existential pain Even though I know that every pain is expressed through the body I need time to learn to distinguish between these different pains in practice Could we talk about this next time?

When I identified with a patient in pain, I found that I wanted to talk about my process, about the things I expenenced with pain Instead, the one who played the nurse asked for aspects regarding content I realized then that I often do the same thing myself with patients I think it is scary to get so intumate or to assume a vulnerable position Is it possible to learn this sort of thing?

By 'sharing' the participants were able to put their own unique experiences, opinions and feelings into words They could also identify with other people's experiences and discover differences In addition, they could also expenence that there was no need for them to live up to the teacher's expectations In this way, a 'total symbiosis' of teacher and participants was avoided and the latter could take responsibility for their own learning process

\section{Negative experiences}

When there is an open and respectful climate, negative feelings can also be brought up In this first session, for example, one of the participants admitted that she felt a bit disappointed A reason for her participation in the programme was that she wanted to become 'stronger' in caring for people in pain In the exercise in which she had to identify with a patient in pain, she had felt weak and vulnerable This was not what she had expected, nor what she had come for

Feedback is important, dealing with and expressing feelings can add to learning By not being opposed to negative feelings and by paying attention to them, the participants were able to experience that negative reactions may sometimes have a positive effect For the teacher, it was also important to hear the negative experiences, as they clanfied the participants' wishes 
Generally speakung, when a teacher listens to such expenences non-defensively, he/she is able to guide the participants in dealing with patients with negative experiences This can be very useful, especially in cases of patients with pain Pain often evokes negative thoughts and feelings ('You just let me suffer from pain', 'If you could only feel what I'm going through') A nurse who has expenenced that she is free to have her own negative thoughts and feelings and even to express them may be better able to identify with a patient, who, as a result of his pain, sometimes considers himself and his surroundings in a negative light

\section{The subsequent sessions}

In the subsequent sessions the themes to which we paid attention in the first session, were further worked out Other main themes which were dealt with were, for example, 'Pain assessment', 'Breathing and pain', 'Pharmacological interventions', and 'Working together in the interest of surgical cancer patients in pain'

No matter what the theme of a particular session was, the approach was in principle the same Readiness was brought about at the beginning of a session, first, by paying attention to what was going on in the here and now', second by sharing ('How did it go last week, and could you do anything with what you learned in the last session ') and finally, by asking which elements participants wanted to learn about in the current session

The teacher made a careful choice, on the basis of the participants' reactions, regarding whether to start with learning in a cognitive or in a more affective way in each session also In the cognitive domain, a particular theme was often introduced by a lecture given by the teacher, or by a group conversation about a relevant article, theme or book Through working in the cognitive domain, the teacher also created readiness for moving on to the affective domain When participants did not have a preference, the teacher started in the affective domain, for example with questions such as Has any of you experience with this theme?', 'Are you willing to share what your expenences are on this theme?', and 'How did you feel then' An important advantage of starting in the affective domain is that this could create a hunger for knowledge', and a meal is more enjoyable when one is hungry'

At the end of each session, the aspect of 'taking responsibility' received attention The common approach was in principle the same as that described earlier by looking back upon that particular session and also by taking stock of what the participants intended to use, these evaluation periods were used to make a 'bridge' between theory and practice, and between the programme and the hospital

\section{CONCLUSION}

To reiterate, confluent education is a way and a process of teaching and learning in which the affective domain and the cognitive domain flow together, like two streams merging into one river We believe this confluence is especially important in (continuing) nursing education concerning topics related to pain After all, a nurse's knowledge, expenence and feelings all determine the quality of the nurse's pain assessment and management If participants were only trained with regard to cognitive aspects (e $\mathrm{g}$ broadening of knowledge about pain assessment tools or pain medication), they might possibly ignore, in practice, the interpersonal processes between them and patients They might also possibly ignore the unique process which occurs in themselves and in each patient In these cases, nurses would not learn to value patients' feelings, ideas and perceptions related to pain If, on the other hand, attention were only pard to the affective domain ( $\mathrm{g}$ the feelings nurses have in caring for patients in severe pain), nurses would not learn to link personal expenences to their knowledge about parn In other words, if too much attention were pard to affective knowledge, the participants might develop a narrow view in which there is insufficient attention to the needs of patients in pain which are not strictly medical

Nursing in general and nursing pain management in particular, depend to a large extend on the knowledge the nurse has acquired Yet in a profession which aims to offer integrated cure and care, educators must not forget that nurses' interventions are also affected by more affective ways of knowing

Last but not least, it is very important for teachers to realize that the learning process is greatly affected by the quality of their relationship with the students (Peterson \& Walberg 1979) For changes in practice, it is necessary that the participants' communication skills and knowhow are built up through interactions between teacher and participants As Brown (1981) states

If the teacher has exatement and enthusiasm and commutment and involvement in his teachung because he is directly connected to his teaching at each moment, there will be a corresponding impact on the student $\mathrm{He}$ can identify with the teacher because he is there to identify with There are ways to learn to be present, to be more totally involved There are ways to learn to make contact and to be avalable for contact for others 


\section{Acknowledgements}

The authors thank George Brown, Marco de Vnes, Bill Solomon, Bert Garssen, Mieke Grypdonck and Huda Huyer Abu-Saad for their inspiring comments

\section{References}

Alexander M A (1990) Evaluation of a training program in breast cancer nursing Joumal of Continuing Education in Nursing 21(6), 260-266

Barber P \& Norman I (1989) Preparing teachers for the performance and evaluation of gaming-simulation in expenentral learning climates Joumal of Advanced Nursing 14, 146-151

Brown G I (1981) Systems, Process and Assorted Constructs University of Calufornia, Santa Barbara

Brown GI (1990) Human Teaching for Human Learning An Introduction to Confluent Education The Gestalt Journal, New York

Brown G I, Yomans, T \& Grzzard L (eds) (1975) The Live Classroom Viking Press, New York.

Brown GI, Phillips M \& Shapiro S (1976) Getting It All Together Confluent Education Phi Delta Kappa Educational Foundation, Bloomington, Indiana

Buber M (1970) -Thou Charles Scribners, New York

Burnard $P$ (1987) Towards an epistemological basis for expenential learning in nurse education Journal of Advanced Nursing 12, 189-193

Castillo G A (1974) Left-Handed Teaching Praeger, New York.

Diekelmann NL (1992) Learning-as-testing a Heideggenan hermeneutical analysis of the lived experiences of students and teachers in nursing Advances in Nursing Science 14(3), 72-83

Erkens M J M (1991) Humanisheke verpleegkunde In De Delta van de Nederlandse Verpleegkunde (Bruggen $\mathrm{H}$ van der ed), De Tydstroom, Lochem, The Netherlands, pp 82-98

Erkens MJM \& Francke AL (1993) De ontwikkeling van een bijscholingsprogramma In Verplegen, interoenieren en evalueren (Francke AL ed), Swets en Zeitlinger, Lisse, The Netherlands, pp 86-106
Francke A.L (1992) Wat doen verpleegkundigen bly pyn? Tijdschrift voor Ziekenverpleging 13, 460-463

French P \& Cross D (1992) An interpersonal-epistemological curnculum model for nurse education Joumal of Advanced Nursing 17, 83-89

Keltner N L (1983) The perceived impact of continuing education on the practice of nurses working in acute care facilities Western Journal of Nursing Research 5, 21-40

Maslow AH (1968) Toward a psychology of being Van Nostrand Reinhold, New York

McCaffery M (1979) Nursing Management of the Patient with Pain JC Lippincott, Philadelphia

McCaffery M \& Beebe A (1989) Pain Clinical Manual for Nursing Practice CV Mosby, St Louis

Miller V G (1989) Analysis and inturtion the need for both in nursing education Joumal of Nursing Education 28, 84-86

Paice J A., Mahon SM \& Faut-Callahan M (1991) Factors associated with adequate pan control in hospitalized postsurgical patients diagnosed with cancer Cancer Nurstng 14(6), 298-305

Perls F S (1970) Gestalt therapy verbatım Highland, New York

Peterson P L \& Walberg H (eds) (1979) Research on Teaching McCutcheon, Berkeley, California

Pritchard, A.P (1988) Management of pain and nursing atttudes Cancer Nursing 11(3), 203-209

Rogers CR (1969) Freedom to Learm Charles E Merrill, Columbus, Oho

Smith MJ (1992) Enhancing aesthetic knowledge a teachung strategy Advances in Nursing Science 14, 52-59

Theeuwen I \& Francke AL (1992) Geremdheid in het uten van pun Verpleegkunde Nederlands-Vlaams Wetenschappelijk Tijdschnft voor Verpleegkundigen 7(2), 75-84

Wake $M$ (1987) Effective instruction in contınuing nursing education Journal of Continuing Education in Nursing 18(6), 188-192 
This document is a scanned copy of a printed document. No warranty is given about the accuracy of the copy. Users should refer to the original published version of the material. 